\title{
Symptom validity testing of feigned dissociative disorder: A simulation study
}

Citation for published version (APA):

Merckelbach, H. L. G. J., Hauer, B. J. A., \& Rassin, E. G. C. (2002). Symptom validity testing of feigned dissociative disorder: A simulation study. Psychology Crime \& Law, 8(4), 311-318.

https://doi.org/10.1080/10683160208401822

Document status and date:

Published: 01/01/2002

DOI:

10.1080/10683160208401822

Document Version:

Publisher's PDF, also known as Version of record

\section{Please check the document version of this publication:}

- A submitted manuscript is the version of the article upon submission and before peer-review. There can be important differences between the submitted version and the official published version of record.

People interested in the research are advised to contact the author for the final version of the publication, or visit the DOI to the publisher's website.

- The final author version and the galley proof are versions of the publication after peer review.

- The final published version features the final layout of the paper including the volume, issue and page numbers.

Link to publication

\footnotetext{
General rights rights.

- You may freely distribute the URL identifying the publication in the public portal. please follow below link for the End User Agreement:

www.umlib.nl/taverne-license

Take down policy

If you believe that this document breaches copyright please contact us at:

repository@maastrichtuniversity.nl

providing details and we will investigate your claim.
}

Copyright and moral rights for the publications made accessible in the public portal are retained by the authors and/or other copyright owners and it is a condition of accessing publications that users recognise and abide by the legal requirements associated with these

- Users may download and print one copy of any publication from the public portal for the purpose of private study or research.

- You may not further distribute the material or use it for any profit-making activity or commercial gain

If the publication is distributed under the terms of Article $25 \mathrm{fa}$ of the Dutch Copyright Act, indicated by the "Taverne" license above, 


\title{
SYMPTOM VALIDITY TESTING OF FEIGNED DISSOCIATIVE AMNESIA: A SIMULATION STUDY
}

\author{
HARALD MERCKELBACH*, BEATRIJS HAUER \\ and ERIC RASSIN \\ Department of Experimental Psychology and Faculty of Law, \\ Maastricht University, The Netherlands
}

(Accepted in final form May 18 2001)

\begin{abstract}
It has been argued that Symptom Validity Testing (SVT) has limited sensitivity in correctly identifying feigned autobiographical memory loss (e.g., dissociative amnesia) because malingerers would easily understand that below change performance on the SVT implies feigned memory loss. The current study tested this assumption in a sample of undergraduate students $(N=20)$ who committed a mock crime and then were instructed to feign complete amnesia for this event. Next, they had to answer 15 forced-choice questions that always contained the correct answer and an equally plausible alternative. Results show that a nontrivial minority of participants $(40 \%)$ performed below chance. As well, understanding the SVT rationale appeared not to be related to random behaviour. Taken together, the results indicate that SVT procedures might be helpful in identifying feigned dissociative amnesia.
\end{abstract}

Keywords: Malingering; Dissociative amnesia; SVT

Although Symptom Validity Testing (SVT) procedures were originally developed to detect malingering of sensory deficits (e.g., deafness; Pankratz, 1979) and short-term memory problems (e.g., Binder and Pankratz, 1987), more recent case studies (e.g., Denney, 1996; Frederick, Carter and Powel, 1995) suggest that SVT might also be fruitfully applied to suspicious memory deficits for autobiographical events (e.g., dissociative amnesia). Briefly, SVT involves a forced-choice

\footnotetext{
*Corresponding author. Prof. Dr. H. Merckelbach, Department of Experimental Psychology, Maastricht University, PO Box 616, 6200 MD, Maastricht, The Netherlands.
} 
procedure in which patients are asked a series of questions about the details of an autobiographical event (e.g., a crime or an accident). For each question, patients must choose between two equally plausible answers one of which is correct and the other is incorrect. Genuine dissociative amnesia for an autobiographical event should result in random performance (i.e., correct and incorrect answers are selected approximately equally often). Below change performance (i.e., the incorrect answer is significantly more often selected then the correct answer) indicates strategic avoidance of correct answers and, therefore, intact memory of the pertinent event. Thus, below change performance would provide clinical evidence of malingered dissociative amnesia.

In the case studies by Frederick et al. (1995) and Denney (1996), SVT was used as a tool for assessing memory deficits of criminal defendants who claimed dissociative amnesia for the events surrounding alleged offences. Both studies concluded that SVT appears to be helpful in correctly identifying feigned memory loss and in this way, may contribute to forensic evaluations regarding, for example, competency to stand trial. This is important because claims of dissociative amnesia by criminal defendants are far from rare. For example, older reviews (e.g., Schacter, 1986) found that $30 \%$ to $65 \%$ of individuals charged with homicide claim amnesia for the crime. More recent studies (e.g., Bourget and Bradford, 1995; Swihart, Yuille and Porter, 1999) noted that claimed amnesia is also frequently observed in sex offenders and husbands who have assaulted their spouse. With this in mind, SVT procedures appear to be a welcome tool for forensic psychologists who are asked to evaluate the validity of dissociative amnesia claims.

Several commentators (e.g., Rogers, Harrell and Liff, 1993) have argued that while SVT procedures virtually never misclassify bona fide patients (i.e., a low false positive rate), they also tend to have low sensitivity rates (i.e., only a minority of malingerers is detected) due to the fact that it is easy for malingerers to understand the rationale behind these procedures. Experimental simulation studies show that this consideration is certainly true for symptom validity testing of short-term memory deficits (e.g., Wiggins and Brandt, 1988). In these studies, participants typically read a case vignette of a patient claiming shortmemory deficits. Next, they are instructed to perform like the patient on a memory test in which to-be-remembered words are presented and then have to be recognized in a forced-choice procedure. Under these con- 
ditions, it might be relatively easy for simulators to discern the rationale behind the test and to calibrate their responses in such way that they fall in the random range. However, individuals who claim dissociative amnesia for a criminal event represent a completely different problem. In such cases, symptom validity testing would pertain to memory for an autobiographical event rather than for a word list presented a few seconds ago. Given the absence of a pre-test phase (e.g., word lists) that clearly defines what should be remembered, simulators in these cases might find it hard to strategically calibrate their responses. The current study was a first attempt to determine to what extent undergraduate participants feigning dissociative amnesia for a crime succeed in performing in the random range on a symptom validity test.

\section{METHOD}

\section{Participants}

Participants were 20 undergraduate psychology students ( 3 men) who were invited to participate in a simulation study in return for a small financial compensation. Mean age was 20 years $(S D=2.3$; range: 19 24 years).

\section{Procedure}

Participants read written instructions that told them to enter a pub that is located in the psychology building. They were not familiar with the pub and there were no other people in the pub. Participants were told to stay for $5 \mathrm{~min}$ in the pub. At the end of that period they had to steal a blue envelope containing 15 guilders (approximately 7 dollars) that lay on top of one of the tables in the pub. Participants were instructed to return to the lab and to imagine that they were suspects in a criminal investigation. More specifically, they were asked to behave in such way as to convince others that they had complete memory loss for their visit to the pub.

\section{Symptom Validity Testing}

After their return from the pub, participants were given a SVT that consisted of 15 two-choice items. Using a Doob and Kirshenbaum 
(1973) pilot procedure, the 15 items had been selected from a larger pool of 25 items. During the pilot, the 25 items were given to a sample of naïve undergraduates $(N=10 ; 3$ men) who were asked to choose the most plausible alternative. Next, mean binomial probabilities were calculated and items with probabilities of correct answers below .3 or above .7 were removed from the set. This procedure resulted in 15 unbiased items that had to do with the money that had been stolen and the details of the pub interior. For each item, participants had to choose between two answer options. Typical examples are "The amount of money stolen was 1.10 guilders or 2.15 guilders"; "The envelope containing the money was 1 . blue or 2 . green" and "In the pub, there is a huge mirror 1. yes or 2. no." For each participant, correct answers were summed to obtain total SVT scores.

After having completed the SVT, participants were asked to stop feigning amnesia. Next, they were once again given the 15 SVT items, but this time participants had to respond honestly. Accordingly, answer options not only included the correct and incorrect alternatives, but also a "don't know" option. Correct answers were summed to determine true memory levels. Participants were then invited to write down what they thought was the purpose of the experiment. Finally, they were fully debriefed, paid, and asked not to discuss the experiment with their colleagues.

\section{RESULTS}

Table I shows the distribution of total SVT scores. Following the binomial formula presented by Spiegel and Castellan (1988; p. 43), 8 participants $(40 \%)$ had total SVT scores below random chance (i.e., total SVT $<4$ ) indicating deliberate avoidance of correct alternatives, while 6 participants $(30 \%)$ performed in the random range. Furthermore, 6 participants $(30 \%)$ displayed above chance level performance (total SVT $>11$ ) indicating that they had made no convincing attempt to feign amnesia.

Raw scores of the 6 participants who performed in the random range were subjected to runs tests in order to determine whether their order of answers followed a random pattern (see for a similar 
TABLE I Distribution of total scores on the 15 -item SVT and the 15-item true memory test $(N=20)$

\begin{tabular}{lcc}
\hline Items Correct & SVT & True memory \\
\hline$<4$ & $8(40)$ & $0(0)$ \\
$4-11$ & $6(30)$ & $7(35)$ \\
$>11$ & $6(30)$ & $13(65)$ \\
\hline
\end{tabular}

procedure, Cliffe, 1992). None of the participants displayed a pattern that significantly departed from random behaviour.

The distribution of true memory performance scores is also shown in Table I. As can be seen, there were no scores in the below-chance range. Indeed, mean SVT scores were considerably lower than true memory levels, means being $6.9(S D=5.4)$ and $11.7(S D=1.9)$, respectively $[t(19)=3.6, P<0.001]$.

Inspection of participants' written accounts of the experiment revealed several interesting things. To begin with, 6 participants thought that the SVT was a meaningless distractor test and that their nonverbal behaviour was observed. Four of these participants belonged to the subgroup that performed above chance on the SVT, while two belonged to the subgroup that had SVT scores within chance expectation. Secondly, 7 participants gave accounts that indicated some understanding of the true rationale behind the SVT. However, only two of them performed in the random range, while 4 of them performed below chance. Apparently, then, the link between random SVT performance and the ability to discern post hoc the rationale behind the SVT is not a straightforward one.

\section{DISCUSSION}

Some authors (e.g., Faust, 1995; Rogers et al., 1993) have argued that as a tool for detecting feigned amnesia in patients, SVT procedures may lack sensitivity due to their simplicity. Thus, these authors assume that respondents will easily recognize the rationale behind SVT and, accordingly will calibrate their responses such that they fall within the random range. Note that this critique is based on the assumption that people have reasonable accurate statistical intuitions, an assumption 
that may be questionable (e.g., Kahneman and Tversky, 1982). This may be particularly true when SVT is applied to autobiographical memory, because in that situation SVT pertains to an event rather than to a clearly defined set of test items (e.g., word lists) for which it is quite obvious what random recognition would imply.

The current simulation study tested to what extent a sample of intelligent people can beat an SVT procedure when they are instructed to feign amnesia for an autobiographical event (i.e., a mock crime). The results demonstrate that a nontrivial minority of the participants $(40 \%)$ significantly performed below chance, which means that they deliberately produced the wrong responses and, therefore, had knowledge about the correct responses. Note that if the 6 participants who obtained above chance SVT scores are removed from the sample, the percentage of participants whose feigned amnesia is detected through below chance performance increases to $57 \%$. As well, after the SVT procedure, 7 participants indicated some understanding of the SVT rationale, but 4 of them nevertheless performed below chance. Keeping in mind that participants were undergraduate students and that our findings might therefore underestimate the sensitivity of SVT procedures, our study suggests that SVT procedures might constitute a valuable challenge test for evaluating claims of dissociative amnesia raised in criminal or civil cases. More generally, the results of the current study concur with the largely anecdotal literature about the efficacy of SVT in detecting malingered dissociative amnesia (e.g., Denney, 1996). Meanwhile, we agree with Faust (1995) that there is considerable room for improvement. For one thing, less transparent versions of the SVT are needed to further reduce the number of individuals who seem to understand the rationale behind SVT. This could be done by adding bogus items (i.e., items that have no correct alternative) to the SVT. It may well be the case that such items interfere with participants' ability to develop a clever strategy to beat the SVT. Furthermore, although the current study as well as the case studies presented by Denney (1996) show that even with a relatively small number of items SVT works reasonably well, there are reasons to believe that increasing the number of items would increase sensitivity of the test. More precisely, runs tests performed on scores of participants who perform in the random range become more powerful when the number of test items increases. 
A potential limitation of the current study is that it relied on a mock crime that may have little ecological validity. Most cases of feigned amnesia described in the forensic literature pertain to violent crimes that involve high levels of arousal (e.g., Swihart et al., 1999). Plainly, this type of crime is difficult to simulate in a laboratory context. On the other hand, there are some isolated case vignettes of amnesia pertaining to fraud (e.g., Kopelman, Green, Guinan, Lewis and Stanhope, 1994).

To sum up, then, the current results provide a basis for cautious optimism regarding the usefulness of the SVT in detecting feigned amnesia. They also suggest that attempts to develop more refined versions of the SVT are worthwhile. One way to accomplish this is by subjecting participants to systematic debriefing sessions. This may yield important clues for optimalizing SVT procedures. However, we also agree with Rogers et al. (1993) that such procedures should be treated as challenge tests. That is, below chance performance is informative, but normal random performance has no meaning.

\section{References}

Binder, L. M. and Pankratz, L. (1987). Neuropsychological evidence of a factitious memory complaint. Journal of Clinical and Experimental Neuropsychology, 9, 167171.

Bourget, D. and Bradford, J. M. W. (1995). Sex offenders who claim amnesia for their alleged offense. Bulletin of the American Academy of Psychiatry and the Law, 23, 299-307.

Cliffe, M. J. (1992). Symptom-validity testing of feigned sensory or memory deficits: A further elaboration for subjects who understand the rationale. British Journal of Clinical Psycholog, 31, 207-209.

Denny, R. L. (1996). Symptom validity testing of remote memory in a criminal forensic setting. Archives of Clinical Neuropsychology, 11, 589-603.

Doob, A. N. and Kirshenbaum, H. M. (1973). Bias in police lineups-partial remembering. Journal of Police Science and Administration, 1, 287-293.

Faust, D. (1995). The detection of deception. In. M. I. Weintraub (Ed.). Malingering and conversion reactions. Neurologic Clinics: Vol 13 (pp. 255-265), Philadelphia: Saunders.

Frederick, R. I., Carter, M. and Powel, J. (1995). Adapting symptom validity testing to evaluate suspicious complaints of amnesia in medicolegal evaluations. Bulletin of the American Academy of Psychiatry and the Law, 23, 227-233.

Kahneman, D. and Tversky, A. (1982). On the study of statistical intuition. Cognition, 11, 123-141.

Kopelman, M. D., Green, R. E. A., Guinan, E. M., Lewis, P. D. R. and Stanhope, N. (1994). The case of the amnestic intelligence officer. Psychological Medicine, 24, 1037-1045.

Pankratz, L. (1979). Symptom validity testing and symptom retraining: Procedures for the assessment and treatment of functional sensory deficits. Journal of Consulting and Clinical Psychology, 47, 409-410. 
Rogers, R., Harrell, E. H. and Liff, C. D. (1993). Feigning neuropsychological impairment: A critical review of methodological and clinical considerations. Clinical Psychological Review, 13, 255-274.

Schacter, D. L. (1986). Amnesia and crime: How much do we know?" American Psychologist, 41, 286-295.

Spiegel, S. and Castellan, N. J. (1988) Nonparametric Statistics for the Behavioral Sciences, New York: McGraw-Hill.

Swihart, G., Yuille, J. and Porter, S. (1999). The role of state dependent memory in. redouts. International Journal of Law and Psychiatry, 22, 199-212.

Wiggins, E. C. and Brandt, J. (1988). The detection of simulated amnesia. Law and Human Behavior, 12, 57-78. 